\title{
Morphodynamics and climate in Taiwan since the Late Pleistocene
}

With almost $36,000 \mathrm{~km}^{2}$ and 22.6 million inhabitants, Taiwan is a densely populated area, especially as, owing to its topography, only parts of the main island can be used for settlements, industry and agriculture. The island is $377 \mathrm{~km}$ long and up to $142 \mathrm{~km}$ wide, and one third of it consists of high mountains with steep fluvial relief and plenty of gravitational slope processes. Of the surface area, $5.12 \%$ exceeds $2500 \mathrm{~m}$ in elevation; $1.16 \%$ is higher than $3000 \mathrm{~m}$.

As one of the world's most geomorphologically active terrestrial surfaces, Taiwan is often hit by natural hazards (Fig. 1). Owing to the tectonic triangle situation between the Eurasian continent and the Philippine Plate, this tropical to subtropical island at the eastern fringe of the Eurasian continental plate is driven by endogenic forces triggering uplift in most parts and subsidence in some areas. Frequent earthquakes are loosening surface material, and vertical and horizontal displacements as well as rockfalls and landslides occur during events with magnitude $>5$, such as the Chi-Chi earthquake in 1999. The East Asian monsoon circulation is the driving climatic factor at present; in addition, typhoons with an average frequency of 3.8 per year exert a great impact on both topography and human resources. With their extremely heavy rainfalls (up to $>1400 \mathrm{~mm}$ in $24 \mathrm{~h}$ ) they are the most important factor in respect to exogenic processes, but lengthy winter rainfalls also activate denudation and fluvial erosion. Precipitation in Taiwan averages about $2500 \mathrm{~mm}$ but varies locally. The western coastal plain and the south have a longterm mean precipitation of $1500-1800 \mathrm{~mm}$, whereas at the north and east coasts the mean annual precipitation is as high as $4800 \mathrm{~mm}$.

The high mountain area of Taiwan with its highest peak Yu Shan (Jade Mountain) $(3997 \mathrm{~m})$ and more than 200 peaks higher than $3000 \mathrm{~m}$ is an isolated high mountain area in East Asia, located at the Tropic of Cancer. It gives an excellent opportunity to study landscape processes at different altitudes, also in connection with the question about the effects of climatic changes and differences in monsoon circulation during the Late Quaternary.

The institutional framework is a cooperation agreement between the Freie Universität Berlin and the National Taiwan University, Taipei. Margot Böse's first scientific stay was in 1996, to learn more about high mountain research in Taiwan and to prepare future field trips by studying maps and aerial photos in the Department of Geology. Much help was given at that time by Ping-Mei Liew who also introduced her to her colleagues in the Department of Geography. At that time, the only references to a Pleistocene high mountain glaciation, based on fieldwork, were by Tanaka and Kano and the German scientist Wolfgang Panzer, travelling with his Japanese colleagues in the early 1930s.

The first modern fieldwork related to questions of a former glaciation started in spring 2000 as a pilot project and was financed by the Deutsche Forschungsgemeinschaft (DFG: Bo 659/15-1), the Deutscher Akademischer Auslandsdienst (DAAD: D/0008237) and the National Science Council, Taiwan, within a PPP-Project. At the same time, Chien-Fu Yang had just started his Ph.D. research on former glaciation in the high mountains. During the following years, a further research grant by the DFG (Bo 659/16-1) enabled us to continue our fieldwork and also to start geochronological studies in cooperation with Andrew Murray, Nordic Laboratory of Luminescence Dating at Risø, Roskilde, Denmark, for optically stimulated luminescence (OSL) dating, and for surface exposure dating (SED) with Christian Schlüchter as scientific supervisor and Susan Ivy-Ochs at the Institut für Teilchenphysik, ETH-Hönggerberg, Zürich (Zürich-Bern-Konsortium).

Research by the group of geomorphologists of the Freie Universität Berlin was related to the highest parts of the mountains in three study areas, Nanhuta Shan, Hsueh Shan and Yu Shan; Hebenstreit et al. present the results. In addition, Hebenstreit reconstructed the ELA of the last glacial phases. Nanhuta Shan, located at the northwestern edge of Taroko National Park and the most remote of the three areas, was the most intensely investigated. Not only traces of Pleistocene glaciations but also little-known, present-day geomorphological processes at and above the tree line were the focus of interest. Questions related to the existence of a periglacial zone and the processes at altitudes above roughly $3000 \mathrm{~m}$ were included in the programme and studied by Klose. For this purpose, the Freie Universität Berlin provided funds to install a meteorological station at $3560 \mathrm{~m}$ a.s.1, measuring precipitation, air temperature and soil temperatures at 2, 10 and $20 \mathrm{~cm}$ depth since March 2001. Thanks to the mountain-guide Wen-Chih Lin for 


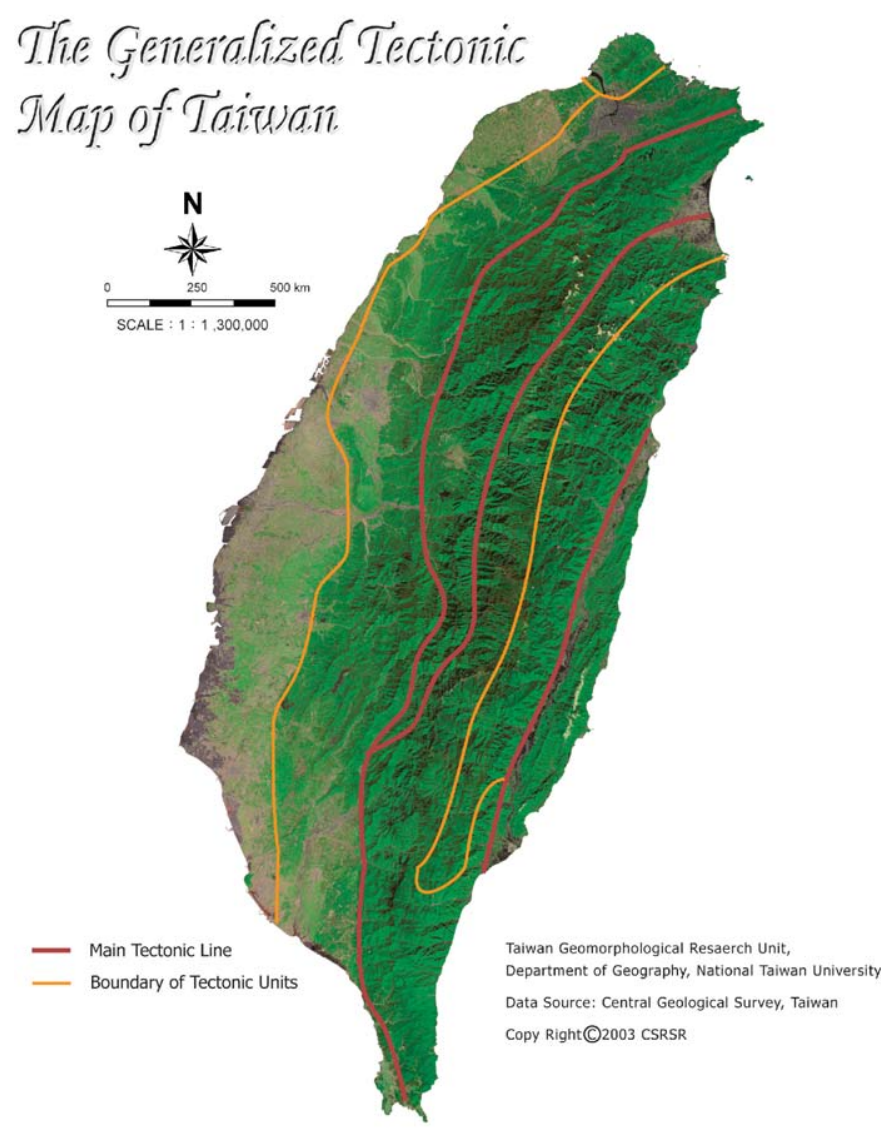

Fig. 1.

taking care of us during our field trips and also for collecting data from the meteorological station. We have to thank the authorities of Pei-Shan National Park, Yu Shan National Park and especially Taroko National Park to give us permission for work.

Most important was the personal and logistic help given in many ways by Jiun-Chuan Lin and his students. Their own research topics are more related to fluvial erosion and denudation in lower parts of the mountains as can be read in the contributions of Jen and Lin et al. We soon found out that the complicated interrelationship between exogenic and endogenic processes in this extraordinary high mountain area has to be understood as a whole system in past and present.

Hence, Jiun-Chuan Lin and Margot Böse decided to hold a symposium in Taipei, which was financed jointly by the Deutsche Forschungsgemeinschaft (DFG: 446 TAI $121 / 3 / 03$ ) and the National Science Council, Taiwan. From 25 to 29 February 2004, a group of scientists from Taiwan, Germany, Switzerland, Denmark, and Great Britain met to consider the topic: Morphodynamics in the mountains of Taiwan since the Late Pleistocene. Thus the symposium was open to discuss various different processes such as fluvial dynamics, slope dynamics, here presented by Chen, and Lin et al., processes above the treeline, former glacial landforms and paleoclimatic reconstruction, supported by palynological data in a long-term record by Liew et al. from lower areas. Lai et al. discuss tectonics and morphology, and $\mathrm{Hu}$ studies the interfingering of tectonic subsidence and human impact enforcing it. So we attempted an approach to an integrated view of landscape formation. The three-day field trip with its intense discussions was very stimulating for the young researchers and gave all of us a lot of ideas. This academic knowledge, as well as its tools, can be used for hazard prevention. In addition we gave information to Pei-Shan National Park, Taroko National Park and $\mathrm{Yu}$ Shan National Park for educational purposes in their exhibition halls.

The main results of the symposium are assembled in this volume, and show the high diversity and the quantitative extent of some of the processes confronting the inhabitants of Taiwan, their economy, and their planning authorities. In future we hope to continue our research to learn more about the denudation and erosion processes affecting this area, in order to improve protection for the population and to reduce the effects of hazard events.

The guest editors of this volume thank the referees whose judicious advice helped to improve the manuscripts. Last but not the least, we thank Dirk van Husen, European editor of Quaternary International for many years, for encouraging the presentation of these papers in a volume.

Margot Böse

Freie Universität Berlin, Department of Earth Sciences, Malteserstr 74-100, D-12249 Berlin, Germany E-mail address: mboese@geog.fu-berlin.de

Jiun-Chuan Lin

Department of Geography, National Taiwan University, No. 1 Sec. 4, Roosevelt Rd. Taipei, Taiwan 106 E-mail address: jclin@ntu.edu.tw 